\title{
Post-traumatic Stress Disorder Post Partum
}

\section{The Impact of Birth on the Prevalence of Post-traumatic Stress Disorder (PTSD) in Multiparous Women}

\author{
Posttraumatic Stress Disorder post partum \\ Über den Einfluss der Geburt auf die Prävalenz einer posttraumatischen Belastungsstörung (PTSD) \\ bei Mehrgebärenden
}

Authors

Affiliation

\section{W. Schwab, C. Marth, A. M. Bergant}

Universitätsklinik für Frauenheilkunde Innsbruck (University Clinic of Gynaecology Innsbruck), Innsbruck

Schlüsselwörter
Geburt
Posttraumatische
Belastungsstörung
Mehrgebärende
Inzidenz
präexistente PTSD
Key words
childbirth
post-traumatic stress
disorder
multiparous women
incidence
pre-existing PTSD

received 13.4.2011 revised $\quad 28.7 .2011$ and 15.9.2011 accepted 9.11.2011

\section{Bibliography}

Dol http://dx.doi.org/ 10.1055/s-0031-1280408 Geburtsh Frauenheilk 2012; 72: 56-63 ๑ Georg Thieme Verlag KG Stuttgart · New York . ISSN 0016-5751

Correspondence
University Professor
Dr. Christian Marth
Universitätsklinik für Frauen-
heilkunde Innsbruck
(University Clinic of
Gynaecology Innsbruck)
Anichstraße 35
6020 Innsbruck
christian.marth@uki.at

\section{Abstract}

Traumatic birth experiences may lead to serious psychological impairment. Recent studies show that a considerable number of women can develop post-traumatic stress disorder (PTSD), in some cases in a subsyndromal form. Until now, the possibility that postpartum psychological symptoms might be a continuum of a pre-existing disorder in pregnancy has rarely been considered. This study therefore aimed to evaluate the proportion of women who develop post-traumatic stress disorder as a result of childbirth.

Materials and Methods: 56 multiparous women were recruited for the study. The diagnosis of PTSD was made according to the criteria for psychological disorders in the DSM-IV (Diagnostics and Statistical Manual of Mental Disorders). The data were collected in structured interviews in the 30th to 38th week of gestation and in the 6th week post partum.

Results: Of the 56 women participating, 52 (93\%) completed the survey. Uncontrolled results showed that $21.15 \%$ of the multiparous women met the full diagnostic PTSD criteria in the 6th week post partum. After the exclusion of all cases already characterised by all criteria or a subsyndromal form of PTSD caused by previous traumatisation, the PTSD rate was below $8 \%$ at 6 weeks postpartum (= incidence rate of PTSD post partum).

Conclusions: The present study is the first prospective longitudinal study to demonstrate the occurrence of full criteria PTSD in multiparous women as a result of childbirth after having excluded pre-existing PTSD. The results of our study show a high prevalence rate of PTSD during pregnancy. A number of women report all aspects of post-traumatic stress disorder as a result of childbirth.

\section{Zusammenfassung \\ $\nabla$}

Traumatisch erlebte Entbindungen können zu erheblichen psychischen Beeinträchtigungen führen. Neuere Forschungsergebnisse legen nahe, dass eine nicht unbeträchtliche Anzahl von Frauen nach der Geburt eine Posttraumatische Belastungsstörung (PTSD) entwickelt, bei vielen kann eine subsyndromale Form diagnostiziert werden. Bislang wurde der Möglichkeit, dass postpartale psychische Symptome ein Kontinuum einer bereits in der Schwangerschaft bestehenden Störung darstellen können, zu wenig Rechnung getragen. Ein Ziel der Studie war es deshalb, zu evaluieren, wie viele Frauen eine Posttraumatische Belastungsstörung als Folge der Geburt/Entbindung entwickeln.

Material und Methoden: 56 Mehrgebärende wurden für die Studie rekrutiert. Die Diagnostik einer PTSD wurde nach den Forschungskriterien des DSM-IV (Diagnostic and Statistical Manual of Mental Disorders) durchgeführt. Daten wurden in der 30.-38. Schwangerschaftswoche und 6 Wochen post partum unter Verwendung strukturierter Interviews erhoben.

Ergebnisse: Von den ursprünglich 56 Teilnehmerinnen beendeten 52 (93\%) die Studie. Unkontrollierte Resultate zeigten eine Prävalenz von 21,15\% der Mehrgebärenden, die 6 Wochen post partum alle diagnostischen Kriterien einer PTSD erfüllten. Nach Ausschluss aller Fälle, die bereits präpartal das Vollbild oder eine subsyndromale Form einer PTSD als Folge früherer Traumatisierungen zeigten, lag die PTSD-Rate 6 Wochen nach der Entbindung unter $8 \%$ (= Inzidenzrate einer postpartalen PTSD).

Schlussfolgerungen: Die vorliegende Studie war die erste prospektive Longitudinalstudie, die das Vorhandensein des Vollbilds einer Posttraumatischen Belastungsstörung als Folge der Geburt bei Mehrgebärenden untersuchte, nachdem Fälle präexistenter PTSD ausgeschlossen wurden. Die 


\section{Introduction and Definition of the Problem}

The birth of a child is one of the most intense and emotional experiences in a woman's life and results in extremes in the perception of this event. Both traumatically experienced childbirth and stressful events in the individual life story of a woman can result in significant psychological impairments post partum. Depending on objective and subjective factors, childbirth can act as a significant stressor and trigger for post-traumatic stress disorder (PTSD), a mental illness which affects a disproportionately high number of women in childbearing age, with a lifetime prevalence of $10.4-13.8 \%$ [1-4].

Post-traumatic stress disorder has only been systematically studied since 1980, after the illness was included in the "American Psychiatric Association" (APA) in DSM-III ("Diagnostic and Statistical Manual of Mental Disorders") [5]. In 1991, it was included in the ICD-10 ("International Classification of Mental and Behavioural Disorders") of the World Health Organisation WHO [6].

According to ICD-10 (F43.1), post-traumatic stress disorder is defined as a protracted response to a stressful event or situation which is exceptionally threatening or of catastrophic proportions. This can be experienced in one's own person or sensed in other persons and would cause deep distress in nearly every individual. According to DSM-IV, affected persons have experienced threat to life, danger to life or severe physical injury, or threat to one's own physical integrity or that of another person. The traumatic experience can lead to unsettling of one's self-image and understanding of the world.

The disorder and its severity are defined not only by the trauma, but also by the subjective reaction to the traumatic event. Both the threat to physical integrity and the threat to the fundamental human experience of being an autonomously acting and thinking person have a traumatising effect.

Post-traumatic stress disorder is characterised by three main symptom clusters: 1. Intrusive re-experiencing (Intrusion). 2. Avoiding of trauma-related stimuli or reduced emotional responsiveness (Avoidance/Numbing). 3. Overreacting (Hyperarousal) (- Table 1).

PTSD occupies a special position within psychological disorders in the classification systems ICD-10 and DMS-IV, in so far as it is not purely descriptive but rather etiopathological. Unlike other mental disorders, a specific cause, namely a previous trauma event is assumed to be the trigger for post-traumatic stress disorder.

In German-speaking countries, the ICD-10 is mainly used. However, the DSM-IV, the criteria for which were also applied in the present study, appears to be better suited for the accurate recording of PTSD. Both diagnostic systems include exposure to trauma and symptoms of a triad of the symptom clusters B, C and D. A subjective criterion exists only in DSM-IV.

It would appear to be obvious to consider childbirth as a potentially traumatising event which can result in the development of PTSD and subsyndromal forms of this disorder [7-8]. Childbirth experienced as traumatic can overshadow the mother-child bond, the general adaptability [9-12] and the partnership [14, $16,18]$ and also negatively influence the decision to have more
Resultate unserer Untersuchung zeigen eine hohe präpartale PTSD-Prävalenzrate. Ein Teil der Frauen weist alle Aspekte einer postpartalen Posttraumatischen Belastungsstörung auf.

children [13-17]. If exacerbated by emotional problems, for some women the perinatal period can be a time in which the greatest vulnerability is experienced.

Various research studies show that nearly one third of all women experience childbirth as traumatic, however only $10 \%$ present with severe stress reactions in the first weeks following delivery [18-19]. It is possible that the number of women with postpartum PTSD also includes cases in which the birth either recalls previous trauma or transfers focus to the birth. The birth experience may also reactivate previous symptoms thought to have been eliminated, leading to a recurrence of PTSD [18]. In order to determine how many women with postpartum PTSD represent new cases of previously unaffected individuals, prospective studies are required which measure current and lifelong PTSD during pregnancy.

PTSD following the birth of a child was first described by Bydlowski and Raoul-Duval [20]. Since the inclusion of post-traumatic stress disorder as a diagnostic category in the third edition of " $\mathrm{Di}$ agnostic and Statistical Manual of Mental Disorders" (DSM-III), both the growing acceptance of the prevalence of the trauma and its psychological consequences have led to a revision of the diagnostic criteria. Based on the expanded view of the stressor criterion in DSM-IV, which also considers the subjective percep-

Table 1 DSM-IV criteria for post-traumatic stress disorder (309.81).

\begin{tabular}{|c|c|}
\hline Criterion A & $\begin{array}{l}\text { Confrontation with a life-threatening event; } \\
\text { Reacting with fear, helplessness or horror }\end{array}$ \\
\hline $\begin{array}{l}\text { Criterion B: } \\
\text { Re-experiencing }\end{array}$ & $\begin{array}{l}\text { The event is reexperienced in one of } 5 \text { ways } \\
\text { 1. Intrusive recollections } \\
\text { 2. Distressing dreams } \\
\text { 3. Flashbacks/reliving of the experience } \\
\text { 4. Psychological distress on confrontation/association } \\
\text { 5. Psychological reactivity on confrontation/ } \\
\text { association }\end{array}$ \\
\hline $\begin{array}{l}\text { Criterion C: } \\
\text { Avoidance + } \\
\text { Numbing }\end{array}$ & $\begin{array}{l}\text { At least three of seven symptoms of avoidance } \\
\text { and impaired responsiveness } \\
\text { 1. Avoidance of trauma-associated thoughts, feelings } \\
\text { and conversations } \\
\text { 2. Avoidance of trauma-associated activities, } \\
\text { situations, persons } \\
\text { 3. Amnesia in terms of the trauma } \\
\text { 4. Decline in interests } \\
\text { 5. Isolation, alienation } \\
\text { 6. Impaired affect } \\
\text { 7. Pessimistic future expectations }\end{array}$ \\
\hline $\begin{array}{l}\text { Criterion D: } \\
\text { Hyperarousal }\end{array}$ & $\begin{array}{l}\text { At least two of five symptoms of increased arousal } \\
\text { 1. Difficulty falling or staying asleep } \\
\text { 2. Irritability/outbursts of anger } \\
\text { 3. Difficulty concentrating } \\
\text { 4. Hypervigilance } \\
\text { 5. Exaggerated startle responses }\end{array}$ \\
\hline Criterion E & Duration of symptoms $(B, C, D)$ is more than one month \\
\hline Criterion $\mathrm{F}$ & $\begin{array}{l}\text { The disturbance causes clinically significant distress or } \\
\text { impairment in social, occupational, or other important } \\
\text { areas of functioning. }\end{array}$ \\
\hline
\end{tabular}


tion of an event, childbirth can, even if not explicitly named meet the criteria for a traumatic event that may cause the onset of PTSD [12].

The published prevalence rates of diagnosed postpartum PTSD are in the range of $1.5 \%$ [21] and 6\% [22]. Apart from all the debates regarding an extension of the conceptual boundaries of the distinguishing features of a traumatic event, it is difficult to draw firm conclusions about the prevalence of PTSD as a result of childbirth due to the numerous methodological shortcomings.

A study published in January 2010 by Alcorn et al. [23] on the prevalence of PTSD resulting from the birth experience was the first major prospective longitudinal study to record all diagnostic criteria for PTSD postpartum as well as consider pre-existing post-traumatic stress disorders and affective disorders. Prior to the publication of this study, the potential consequences of PTSD diagnosed in pregnancy had never been investigated and the potential impact of antenatal factors and affective disorders on the subsequent development of a birth-related stress disorder [14] had never been taken into account. Consequently, it was not possible to determine whether the observed PTSD symptoms are based on birth events or reflect a pre-existing intrapersonal imbalance [21].

The objective of our study was to determine which demographic and obstetric characteristics act as significant predictors of a post-traumatic stress disorder and whether, to what extent, and with which symptomatic focus, the characteristics of PTSD must be observed as a result of the birth experience in multiparous women. In this context, for the first time, it was necessary to differentiate exactly between the prevalence and the incidence of a post partum stress disorder, as it could be assumed that a large number of subjects in the study population of multiparous women had a pre-existing trauma and that childbirth could lead to an exacerbation of this disorder. New cases of PTSD had to be examined in-depth, as it could be postulated that the birth event represents a trigger for the onset of post-traumatic stress disorder.

\section{Materials and Methodology of the Studies \\ $\nabla$}

The present study is a prospective longitudinal study using a descriptive design for the recording of prevalence and incidence of post-traumatic stress symptoms in multiparous women within 6 weeks post partum.

\section{Study population}

The study was conducted at the University Clinic of Gynaecology and Obstetrics in Innsbruck. During the period from July 2008 to January 2009, 56 subjects meeting the defined inclusion criteria: 36 th to 38th week of gestation, German as mother tongue or sufficient knowledge of German, of legal age, no acute mental illness (no F diagnoses, not in psychiatric treatment at the time of the study) and who had consented to take part, were included in the study. For participation in the study, at least one birth was to have preceded the current pregnancy, as a second study examining the impact of childbirth on the prevalence of post-traumatic stress disorder in multiparous women was being performed simultaneously.

\section{Study time points}

1. 30th to 38th week of gestation ( $\left.t_{1}\right), 2.6$ weeks post partum $\left(t_{2}\right)$. At study time point $t_{2}$, the subjects were contacted by telephone and a structured interview was conducted. This time frame was selected in order to meet the DSM-IV criterion for the duration of symptoms over a minimum of four weeks.

\section{Measuring instruments}

In the 30th to 38th week of gestation, the subjects were given the socio-demographic questionnaire, the "Life Stressor Checklist" and the "Post-traumatic Stress Diagnostic Scale" for self-assessment. Six weeks post partum, retrospective questions about the birth were asked in a structured telephone interview. Subjects were again asked to answer the questions of the PDS and the "Edinburgh Postnatal Depression Scale."

In the study's socio-demographic questionnaire, general demographic variables were collected. At time point $t_{1}$, prospective questions about the upcoming birth were asked; 6 weeks post partum, retrospective questions about the birth were asked in a telephone interview.

The "Life Stressor Checklist-Revised" (LSC-R) was developed by Wolfe et al. in 1996 [24] as a screening tool for events which meet the criteria for post-traumatic stress disorder according to DSM-IV. The checklist evaluates particularly sensitive femalespecific stressors and has established itself as a well-tolerated instrument for clinical and scientific purposes.

The "Posttraumatic Stress Diagnostic Scale" (PDS), a screening tool for PTSD, was developed by Foa et al. [25] in 1997 in order to demonstrate the shortcomings of pre-existing self-report scales. The PDS is in strict accordance with the DSM-IV criteria and can be used for categorical and dimensional diagnostic purposes. The scale thus has the special advantage of being used both as a DSM-IV diagnostic criterion and for the assessment of the severity of the PTSD's symptoms, with excellent statistical indicators, namely a sensitivity of 0.89 and a specificity of 0.75 . The scale, which includes 49 items, assesses current post-traumatic stress disorders of the event which has caused the surveyed person the most worry. In Part 1, traumatic events in the medical history are recorded; Part 2 contains the survey of the time criterion and the A criteria for the DSM-IV. In the present study both parts could be neglected, as pre-existing traumas were recorded by the LSC, or at time point $t_{2}$ of the survey a preceding childbirth was explicitly indicated as a traumatising event. In the third part, the frequency of 17 symptom items during the last four weeks can be assigned on a four-part Likert scale (DSM-IV criteria B, C and $\mathrm{D}$ ). The calculated sum score values can therefore have values from 0 to 51 . The calculation of sub-scale scores is performed by adding the respective item answers; the total sum score provides information on the severity of the symptoms. As a personal information instrument, the PDS was designed to quickly and efficiently identify PDS persons with post-traumatic stress disorder and to quantify their symptoms.

The "Edinburgh Postnatal Depression Scale" (EPDS), a selfassessment scale of ten items, was developed by Cox et al. [26] according to the symptoms of postpartum depression. The EPDS was specifically designed for the diagnosis of depressive disorders in the postpartum period. Each of the ten items offers has four response options (from 0 to 3), depending on the severity of the symptoms. The total score can therefore lie between 0 and 30 . In the present study, the German-language version of the EPDS (Bergant et al. 1998) [27] was used, with cut-off sum scores of $>9.5$ indicating a depressed mood and scores of $>12.5$ indicating 
a depressive illness. The answers should reflect the state of health in the past seven days.

\section{Statistical Procedure \\ $\nabla$}

All collected parameters are encoded with a number and entered into an SPSS protocol. The analysis of the data collected was conducted in the form of descriptive statistics, as well as tabular and graphical analyses in the "SPSS Statistics" Version 17.0 (Statistical Package for the Social Sciences) and in Microsoft Excel 2007. Correlations between ordinal scale variables were calculated by the "Spearman Rank Correlation". The "Wilcoxon" test, a non-parametric test for comparing two related samples containing quantitative characteristics, was used for the comparative examination of the pre-and postpartum PDS values. When examining the individual characteristics for significant differences through a correlation coefficient (Spearmans Rho), a significance level of $\mathrm{p}<0.05$ was considered to be significant and a level of $\mathrm{p}<0.001$ as highly significant. The confidence interval was $95 \%$.

\section{Results}

$\nabla$

The age of study participants was between 21 and 46 years (median 30 years, mean 31 years, SD 5.8 years). 58\% were married, $38 \%$ unmarried and $4 \%$ divorced. One in four women had a university degree. 5 patients suffered from a chronic or current physical illness, $15 \%$ of the pregnant women had undergone psychiatric treatment in the past, and $8 \%$ indicated having taken psychotropic drugs in the course of their medical history. $85 \%$ of the women had planned their pregnancy. 52 women of the 56 recruited subjects also completed the second part of the study with the postpartum telephone interview. The dropout rate was therefore $7 \%$.

The "Life Stressor Checklist (LSC)" was used for the assessment of criterion A of a post-traumatic stress disorder at the Gynaecological Clinic in Innsbruck. According to the study participants, the lifetime prevalence of one or more traumatic events was $83 \%$. In the pre-partum survey, five women (10\%) reported a traumatic birth experience and a quarter of the subjects reported having experienced a difficult time following an abortion or miscarriage at some point in time. A medical history of traumatic childbirth resulted in significant increases in the EPDS scores postpartum $(p=0.007 / r=0.367)$, which in three of the five traumatised women was above the cut-off limit of 12.5 . Depressive symptoms were therefore confirmed for $60 \%$ of the women affected. By contrast, an abruption or abort in the medical history resulted in no significant correlations with the occurrence of post-traumatic stress disorder $(\mathrm{p}=0.506 / \mathrm{r}=0.094)$ or postpartum depression $(\mathrm{p}=0.703 / \mathrm{r}=0.054)$.

$50 \%$ of the woman delivered vaginally, $31 \%$ gave birth by primary (elective) caesarean section, and a further 19\% $(n=10)$ delivered by secondary caesarean section. A vaginal operative delivery by vacuum was not necessary in any case. $80 \%$ of the study participants undergoing a secondary caesarean section reported "re-experiencing". In the group of women who had undergone an elective caesarean section, the percentage was $75 \%$. In the mothers who had delivered spontaneously the proportion was, remarkably, $62 \%$. No significant correlations were detected between the mode of delivery and the occurrence of depressive symptoms $(\mathrm{p}=0.44 / \mathrm{r}=0.109)$ or post-traumatic stress disorder $(\mathrm{p}=0.41 /$ $r=-0.117)$.

The fear of childbirth could be rated on a scale of 7 from "no fear" to "very high level of fear". A quarter of the women reported no fear of childbirth, $29 \%$ rated their fear of the upcoming delivery as low, a further $27 \%$ as moderate, $15 \%$ as medium, none as high and $2 \%$ as very high. Significant correlations were found between the fear of childbirth and the PTSD criterion of "Re-experiencing" in the 30th to 38th week of gestation ( $p=0.024 / r=0.279)$ and the DSM-IV category "Hyperarousal" post partum ( $p=0.045$ / $r=0.279$ ), while an increased fear of childbirth was not reflected in higher TSD scores $(\mathrm{p}=0.15 / \mathrm{r}=0.202)$.

The stress experienced due to childbirth could also be rated on a scale of 7 from "no stress" to "very high stress". $27 \%$ of the women confirmed that they were not stressed in any way by the childbirth process and $15 \%$ reported low childbirth stress. Two mothers rated stress by childbirth process as moderately high and 6 women each (12\%) as high or very high. Statistically significant correlations were found between the mode of delivery, fear of childbirth and resulting stress $(\mathrm{p}=0.001$ and $0.017 / \mathrm{r}=0.441$ and $0.33)$. The stress resulted in increased occurrence of the criteria "Re-experiencing" $(\mathrm{p}=0.022 / \mathrm{r}=0.318)$ and "Hyperarousal" ( $\mathrm{p}=0.000 / \mathrm{r}=0.503$ ) post-partum. The Spearman's Rank Correlation showed statistically significant values for the development of full criteria for postpartum PTSD ( $\mathrm{p}=0.028 / \mathrm{r}=0.304)$ as well as depressive symptoms $(p=0.003 / r=0.407)$ and the reported birth stress.

At time point $t_{1}$ of the survey (30th to 38th week of gestation), 9 study participants (17\%) presented with full post-traumatic stress disorder. Criterion B ("Re-experiencing") affected only 18 women (35\%). "Avoidance" symptoms were detected in 9 women (17\%) and criterion C in a further 14 pregnant women (27\%).

In the second part of the study (6 weeks postpartum) 7 (78\%) of the originally 9 affected patients still displayed full criteria for PTSD; the incidence of postpartum stress disorder could be diagnosed in four women (8\%). A total of 11 cases of post-traumatic stress disorder post partum were documented, corresponding to $21 \%$ of all study participants ( Fig. 1 ).

The existence of a partial or subsyndromal form of post-traumatic stress disorder, which can be diagnosed in accordance with Stein et al. [28], if in addition to criterion B ("Re-experiencing") at least one symptom of category C ("Avoidance"|"Numbing") and/ or D ("Hyperarousal") is present, was detected in 5 pregnant women. Postpartum, this number increased to 22 (42\%, RR 4.4 and $\mathrm{p}<0.001)$.

The Wilcoxon test, a non-parametric test for the comparison of two related samples with quantitative characteristics, was used to compare the calculated PDS-d- 1 scores of the study time points $t_{1}$ and $t_{2}$ and showed significance values of 0.001 .

The sum score of the "Edinburgh Postnatal Depression Scale" can have values from 0 to 30. In the present study an EPDS cut-off of 9.5 was defined as an indicator for a depressive state. Values $>12.5$ indicated a depressive symptomatology. 4 patients were assigned to the first category and 11 to the second category.

The resulting EPDS scores ranged from 0 to 25, with a median of 5.5 (mean 7.1, SD 5.73). Significant correlations could be found between the EPDS scores and birth stress $(p=0.002 / r=0.422)$, the subjective perception of family support $(p=0.004 / r=0.396)$, the witnessing of a serious accident $(\mathrm{p}=0.043 / \mathrm{r}=0.281)$ and forced sexual contact $(p=0.012 / r=0.344)$. The experience of a traumatic birth resulted in a relative risk of 3.5 for exceeding the cut-off-value of 12.5. Statistical analyses of the EPDS scores in 


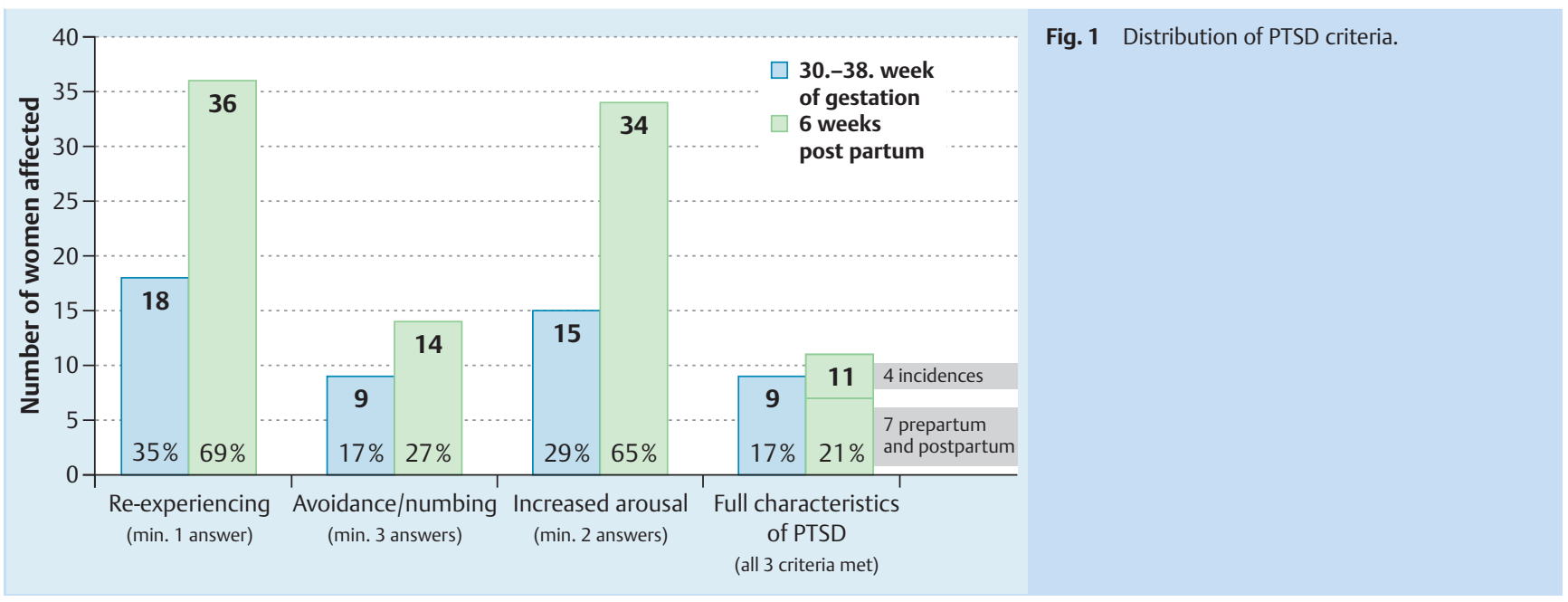

correlation with the PTSD categories "Re-experiencing" ( $\mathrm{p}=0.004 / \mathrm{r}=0.397)$ and "Numbing" $(\mathrm{p}=0.002 / \mathrm{r}=0.488)$ after delivery and the presence of full criteria for postpartum post-traumatic stress disorder $(\mathrm{p}=0.000 / \mathrm{r}=0.531)$ resulted in highly significant results in each case ( $\bullet$ Fig. 2 ).

\section{Discussion/Conclusions}

$\nabla$

Affective disorders in the postpartum period occur relatively frequently. The puerperium is a time of particular vulnerability. The specific symptoms may be temporary or persistent. This may be accompanied with significant functional impairment. In some cases this can even develop into a post-traumatic stress disorder which requires treatment, with potential negative impact on the health status of the woman, the partnership and initially on the particularly fragile mother-child relationship, as well as on subsequent pregnancies.

The prevalence rate of Post-traumatic Stress Disorder post partum in the participants of the Innsbruck study was contrary to our expectations and hypothetical presumption that the study population of multiparous women would result in a low proportion of women developing PTSD or dealing more easily with childbirth trauma. The value of $21 \%$ was four times as high as the published $3 \%$ of the study conducted by Czarnocka and Slade [29], 8\% higher than the study of Wijma [7], 5.6\% higher than the study of Creedy [30] and 6\% higher than the study of Menage [22]. Accordingly, 11 of the 52 participants of our prospective study presented with full criteria for post-traumatic stress disorder. Intensive literature research shows that this ratio had not been reported in any other study. The fact that $17 \%$ of the women surveyed $(n=9)$ already showed full criteria for post-traumatic stress disorder prior to childbirth is also remarkable. Postpartum, this number increased to $21 \%(n=11)$, however two of the patients who originally presented symptoms showed a remission of post-traumatic stress disorder following the birth of the child. A partial PTSD according to Stein et al. [28] was detected postpartum in 22 (42\%), and prepartum only in 5 (10\%) of our subjects. This is a statistically significant result. Here again, differences were observed compared with other studies. The study of Alcorn et al. [23], published as recently as 2010, indicates a percentage of $4.4 \%$ for a subsyndromal form of PTSD prepartum and an increase of only $2 \%$ postpartum. In view of our study results, this represents an inverse development.

In awareness of the unexpectedly high prevalence rates of posttraumatic stress disorder of $17 \%$ of all study participants prepartum and $21 \%$ postpartum, the main focus of our work had to be on the precise differentiation of postpartum point prevalence and incidence, as PTSD diagnosed following childbirth could represent either an aggravation of pre-existing symptoms or a continuation of PTSD which was already present praepartum.

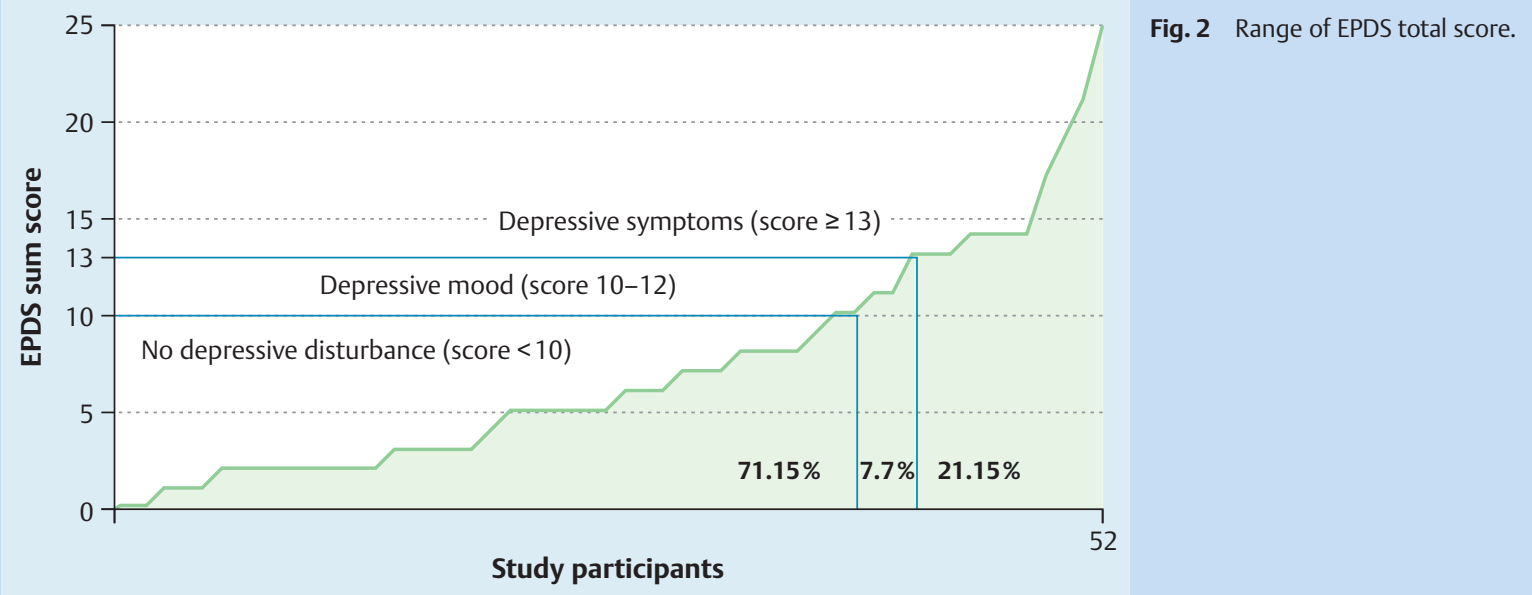


At the beginning of our surveys in 2008, only two prospective longitudinal studies on the development of post-traumatic stress disorder as a result of childbirth were available. The study of Ayers [21], which demonstrated a PTSD incidence rate of $1.5 \%$ 6 weeks postpartum, which however failed to consider a potentially existing PTSD prepartum, and second study of Söderquist [31] with a trauma incidence rate of $3 \%$, which did not consider a potentially pre-existing PTSD and with a trauma definition which did not comply with the guidelines of the DSM-IV. Only the paper published by Alcorn et al. in January 2010 [23] on the prevalence of post-traumatic stress disorder resulting from the birth experience included all diagnostic criteria for PTSD postpartum for the first time and simultaneously evaluated pre-existing PTSD and affective disorders prepartum. This first major prospective longitudinal study now showed a PTSD rate of $1.2 \%$ 4-6 weeks postpartum for women without prepartum symptoms, with an unadjusted rate of 3.6\%. After adjustment of the point prevalence rates of $21 \%$ for cases with existing prepartum full criteria for post-traumatic stress disorder, our study showed a childbirth associated PTSD incidence rate of $8 \%$ of puerperium. Compared with Alcorn's study results, this is again a significantly higher value. However, when comparing the results of our study with those of the study by Alcorn et al ( $21 \mathrm{vs.} 8 \%$ ), an analogous relation could be observed. A comparison of both studies appears to be particularly valid, as in both researches the same measuring instruments were applied for collecting of the statistical data, namely the PDS and the EPDS.

\section{Incidence cases}

Our study results demonstrate that 11 out of 52 study participants presented full criteria for post-traumatic stress disorder, four of these for the first time (= incidence of $8 \%$ ). At the time of the initial survey in the 30th to 38th week of gestation, one of these four women presented with partial PTSD, while another pregnant woman only met criterion B of PTSD and two subjects were asymptomatic prior to delivery.

A comparison of the data collected for the incidence cases with the data of the entire study population showed a higher average age of subjects with newly diagnosed PTSD postpartum. All women who presented with PTSD as a result of traumatic childbirth had undergone a caesarean section. In two cases an emergency caesarean section was the cause of the subsequent trauma. $50 \%$ rated the childbirth as very stressful, $25 \%$ perceived the birth stress as high and a further $25 \%$ as low. Three-quarters of the pregnancies were planned.

In many cases, due to diagnostic overlap, women with PTSD also presented with postpartum depressive symptoms [9]. Postpartum non-psychotic depression is the most common complication of childbirth and affects nearly $13 \%$ of all women [14]. While severe postpartum depression can be easily detected, a less severe presentation is quickly dismissed as a normal or natural result of childbirth. Currently, postpartum depression is only routinely detected with EPDS, as it is common practice to use EPDS as a screening instrument for depressive symptomatology 6 weeks postpartum. This could be the reason that up to $25 \%$ of women with full criteria for PTSD remain undiagnosed, as they do not present with additional depressive symptoms. In this context, it appears worth mentioning that $10 \%$ of our study subjects $(n=5)$ showed an EPDS score of $>12.5$, however did not meet all the DSM-IV criteria for post-traumatic stress disorder. Although not a symptom of depression per se, the tendency to intrusive memories is a cognitive characteristic of depression which is closely associated with its persistence. The dysfunctional significance of intrusive memories correlates positively with intrusion related distress, the existence of cognitive avoidance strategies and depression. A negative assessment of intrusive memories correlates with the occurrence of depression and is the best predictor of depression. Although the majority of postpartum depression is selflimited and vanishes a few months after onset, childbirth is indeed the trigger for recurrent or chronic episodes of depressive disorders for some women.

The conflicting results regarding the role of the mode of delivery in the development of post-traumatic stress disorder suggests that the relationship between mode of delivery and PTSD is not clearly linear. Ryding's study [32] provided verification that invasive procedures increase the risk of the development of PTSD. In this context, an association between emergency caesarean sections and postpartum emotional problems was revealed. The reason for this could be the unpredictability of the event. Chamberlain [33] evaluates a caesarean section as traumatic only when it is performed as an emergency procedure. Czarnocka and Slade [29], however, do not consider the mode of delivery as decisive for the development of a postpartum disorder. Following the statistical analysis of all variables, our study showed no significant correlation between the mode of delivery and the development of full criteria for PTSD or of subsyndromal forms of the disorder. The mode of delivery also did not appear to have an impact on the EPDS score. A highly significant correlation existed only between the type of delivery and the level of the resulting stress. The incidence of post-traumatic stress disorder postpartum showed a different picture; in this case all women had delivered operatively (50\% primary caesarean section, $50 \%$ secondary or emergency caesarean section)!

While Söderquist et al. [31] could demonstrate a significant correlation between post-traumatic stress disorder and an emergency caesarean section, the majority of women presenting PTSD symptoms had delivered vaginally, which implies that a "normal" spontaneous birth can be perceived as traumatising, however an emergency caesarean section does not necessarily have to result in trauma. This suggests that the occurrence of PTSD symptoms as a result of an emergency caesarean section depends both on the individual mother's ability to cope with the situation and on the circumstances of the delivery [34].

According to Ringler's findings [35], it is difficult "outside of the context of individual case studies to differentiate between fear of birth sui generis and other problems associated with pregnancy and personality variables, which are easier to verbalise due to the social acceptance of fear of birth". The fear of birth experienced by multiparous women can often not be linked to specific difficult circumstances of a previous birth. Some women experience trauma in births which are considered as "normal" deliveries from an obstetric point of view and who interpret this as a threat to their physical and psychological integrity. Psychological perception does not necessarily have to correlate with the physical processes. In the present study, significant correlations could only be observed between fear of birth and the PTSD category "Reexperiencing" when surveyed during pregnancy and in category $\mathrm{D}$ ("Hyperarousal") in the secondary survey over the phone following childbirth.

Pregnancy and the time immediately after childbirth is a period in which support by the partner or family members and friends and living in a trusting relationship are particularly important for mental health. However, the perception of supportive assistance is always subjective [18] and based on a multi-dimensional con- 
cept. Different types of social support play an important role in the perception of an event and mediate subsequent reactions. Subjective birth stress and support received by family members and friends has a significant impact on the EPDS score level post partum and thus on the occurrence of various degrees of severity of depressive symptoms. The degree of assistance correlated significantly with the perception of the birth stress and postpartum "Numbing" and "Hyperarousal" symptoms and full criteria for PTSD.

The evaluation of the impact of childbirth on the development of Post-traumatic Stress Disorder was the focus of our study. The study participants who had a medical history of a traumatic birth experience were therefore subjected to a closer examination. Following a statistical analysis of all collected variables, no significant correlation could be detected between a medical history which included a traumatic childbirth and the development of full criteria for PTSD or a subsyndromal form thereof. When examining the EPDS sum scores however, one could determine that patients with a history of traumatic childbirth had significantly higher scores. In the second survey, 6 weeks after the current delivery, $60 \%$ of the women who had suffered trauma through a birth experience presented with a depressive symptomatology, one patient was in a depressive state, and only one woman experienced no symptoms at all.

It is an accepted fact that severe or life-threatening trauma represents risk factors for the development of psychiatric disorders, including PTSD and depression [36]. Women are exposed to different traumatic events than men, with higher rates of sexual and domestic violence, both associated with the highest rate of posttraumatic stress disorder [37]. Most studies on prepartum and postpartum depression and postpartum stress disorders, however, have failed to record abuse and violence in the subjects' history as potential risk factors. $83 \%$ of all women who participated in our study at the Gynaecological Clinic in Innsbruck reported at least one traumatic experience in their past. Every fourth woman had experienced a difficult time due to an abortion or miscarriage and $10 \%$ had experienced traumatic childbirth. Experience of abuse and unwanted sexual touching showed a significant statistical correlation with an occurrence of full criteria for PTSD. Family violence and abuse by a known person suffered under the age of 16 years were accompanied by a limited responsiveness post partum. Involuntary oral, genital or anal sex under the age of 16 years resulted in an increase of the symptoms for re-experiencing post partum.

The prospective study, with the aim of assessing the impact of birth on the development of post-traumatic stress disorder in multiparous women, produced unexpected results. $21 \%$ of the traumatised women meeting the full criteria for post-traumatic stress disorder postpartum has never before been reported in any other publication. Moreover, every fifth woman of our study population met all the DSM-IV criteria for PTSD and thus the criteria for a mental disorder. Additionally, a subsyndromal form of PTSD was observed in $42 \%$ of the study participants. As our study also recorded prepartum symptoms of PTSD, partial PTSD could be detected in $10 \%$ and full criteria for PTSD in $17 \%$ of the pregnant women already during pregnancy. Furthermore, in $21 \%$ of all subjects, depressive symptomatology could be observed postpartum and, in 7\%, a depressive state. The presence of both PTSD postpartum and postpartum depression, however, can be regarded as the product of various etiological causes and as largely unrelated psychological disorders.
A limitation of the results of the present study could be that the main variables of the study, namely the criteria for PTSD or depression, were determined by self assessment scales and a semistructured interview and therefore can be only conditionally compared with the results of clinical-diagnostic procedures.

Psychological trauma as a vital discrepancy experience between threatening situational factors and the individual woman's ability to cope with the situation can result in the development of post-traumatic stress disorder. No correlating stressors which acted as triggers for PTSD could be detected in our study subjects. Whether a traumatic experience manifests itself as a mental disorder appears to depend upon many risk factors. A multi-factorial model is assumed for the origin of PTSD, in which the subjective evaluation of events plays a dominant role.

It appears to be of paramount importance that the information about the clinical picture of PTSD postpartum is distributed amongst doctors in order that more attention can be given to this problem. This is the only way that screening programmes can become established, treatments recommended and appropriate treatment steps initiated. The diagnosis of "PTSD" can prove difficult due to the heterogeneity of the presentation and the reluctance of the patients to speak about past trauma. A secondary prevention, i.e. early diagnosis, is a means for reducing postpartum morbidity in mothers and thus minimises health implications. Furthermore, the urgent need for treatment of PTSD and postpartum depression must be emphasised, as neglect or infanticide could, in a worst case scenario, result in the death of the child or a suicide in the death of the mother [30-40].

A majority of those affected recover from traumatic events without professional help. However, social and cultural factors can be a hindrance to natural healing [3]. Psychopharmacological and psychiatric interventions can rapidly improve symptoms. The application of a customised cognitive-behavioural therapy may also prove successful [41]. Due to the complexity of PTSD, multi-disciplinary expert teams play an important role. One of the biggest challenges is the early detection of this psychological disorder. The task is to identify women with risk factors and to standardise diagnostic procedures.

\section{Conclusion for Practice}

$\nabla$

The high prevalence rate of PTSD in woman of childbearing age should result in the consideration of this disease pattern in gynaecological practice in differential diagnosis. This is the only way that affected patients can be provided with the necessary treatment in order to avoid chronification of this disorder. The benefit of early detection and therapy of post-traumatic stress disorder in pregnancy consists of the prevention and minimisation of unfavourable physical and psychological effects on mothers and their newborn.

The EPDS is a simple and user-friendly tool for the identification of women with depressive symptomatology in the postpartum period.

\section{Conflict of Interest}

$\nabla$

None. 


\section{References}

1 Yehuda R. Post-traumatic stress disorder. N Engl J Med 2002; 346: 108114

2 Yule W. Posttraumatic stress disorder in the general population and in children. J Clin Psychiatry 2001; 62 (Suppl. 17): 23-28

3 Shalev AY. Belastung versus traumatische Belastung. Von homöostatischen Akutreaktionen zur chronischen Psychopathologie (Stress versus traumatic Stress. From homeostatic acute Reactions to chronic Psychopathology). In: van der Kolk BA, McFarlane AC, Weisaeth L, eds. Traumatic Stress. Grundlagen und Behandlungsansätze (Principles and Approaches to Treatment). Paderborn: Junfermann; 2000: 97-116

4 Meyer C, Steil R. Die Posttraumatische Belastungsstörung nach Verkehrsunfällen. (Post-traumatic stress disorder after traffic accidents). Unfallchirurg 1998; 101: 878-893

5 American Psychiatric Association. Diagnostic and statistical manual of mental disorders. 4th ed. Washington, DC: American Psychiatric Association; 1994 [German: Diagnostisches und statistisches Manual psychischer Störungen: DSM-IV. Göttingen: Hogrefe; 1998]

6 Dilling H, Freyberger HJ, World Health Organisation (WHO), eds. International classification of mental disorders. ICD-10 Chapter V (F). Bern: Huber; 1999

7 Wijma K, Söderquist MA, Wijma B. Posttraumatic stress disorder after childbirth: A cross sectional study. J Anxiety Disord 1997; 11: 587-597

8 Olde E, van der Hart 0 , Kleber RJ et al. Peritraumatic dissociation and emotions as predictors of PTSD symptoms following childbirth. J Trauma Dissociation 2005; 6: 125-142

9 Ballard CG, Stanley AK, Brockington IF. Post-traumatic stress disorder (PTSD) after childbirth. Br J Psychiatry 1995; 166: 525-528

10 Allen S. A qualitative analysis of the process, mediating variables and impact of traumatic childbirth. J Reprod Infant Psychol 1998; 16: 107-131

11 Soet JE, Brack GA, Dilorio C. Prevalence and predictors of women's experience of psychological trauma during childbirth. Birth 2003; 30: 30-46

12 Beck CT. Post-traumatic stress disorder due to childbirth: the aftermath. Nurs Res 2004; 53: 216-224

13 Fones $C$. Posttraumatic stress disorder occuring after painful childbirth. J Nerv Ment Dis 1996; 184: 195-196

14 Bailham D, Joseph S. Post-traumatic stress following childbirth: a review of the emerging literature and directions for research and practice. Psychol Health Med 2003; 8: 159-168

15 Ryding E, Persson A, Onell C et al. An evaluation of midwives' counseling of pregnant women in fear of childbirth. Acta Obstet Gynecol Scand 2003; $82: 10-17$

16 Beck CT. Birth trauma: in the eye of the beholder. Nurs Res 2004; 53 : 28-35

17 Beck CT, Watson $S$. Subsequent childbirth after a previous traumatic birth. Nurs Res 2010; 59: 241-249

18 Ayers $S$. Delivery as a traumatic event: prevalence, risk factors, and treatment for postnatal posttraumatic stress disorder. Clin Obstet Gynecol 2004; 47: 552-567

19 Ayers S, Joseph S, McKenzie-McHarg K et al. Post-traumatic stress disorder following childbirth: current issues and recommendations for future research. J Psychosom Obstet Gynaecol 2008; 29: 240-250

20 Bydlowski M, Raoul-Duval A. Un avatar psychique méconnu de la puerpéralité: la névrose traumatique post-obstétricale. Perspect Psychiatr 1978; 4: 321-328

21 Ayers S, Pickering AD. Do women get posttraumatic stress disorder as a result of childbirth? A prospective study of incidence. Birth 2001; 28: $111-118$
22 Menage J. Post-traumatic stress disorder in women who have undergone obstetric and/or gynaecological procedures. J Reprod Infant Psychol 1993; 11: 221-228

23 Alcorn KL, O'Donovan A, Patrick JC et al. A prospective longitudinal study of the prevalence of post-traumatic stress disorder resulting from childbirth events. Psychol Med 2010; 11: 1-11

24 Wolfe J, Kimerling R. Gender Issues in the Assessment of posttraumatic Stress Disorder. In: Wilson J, Keane TM, eds. Assessing psychological Trauma and PTSD. New York: Guilford; 1997: 192-238

25 Foa E, Cashman L, Jaycox $L$ et al. The validation of a self-report measure of posttraumatic stress disorder: the Posttraumatic Diagnostic Scale. Psychol Assess 1997; 9: 445-451

26 Cox JL, Holden JM, Sagovsky R. Detection of postnatal depression. Development of the 10-item Edinburgh Postnatal Depression Scale. $\mathrm{Br}$ J Psychiatry 1987; 150: 782-786

27 Bergant AM, Nguyen T, Heim K et al. [German version and validation of the Edinburgh depression scale]. Dtsch Med Wochenschr 1998; 123: 35-40

28 Stein MB, WalkerJR, Hazen AL et al. Full and partial posttraumatic stress disorder: findings from a community survey. Am J Psychiatry 1997; 154: $1114-1119$

29 Czarnocka J, Slade P. Prevalence and predictors of post-traumatic stress symptoms following childbirth. Br J Clin Psychol 2000; 39: 35-51

30 Creedy DK, Shochet IM, Horsfall J. Childbirth and the development of acute trauma symptoms: incidence and contributing factors. Birth 2000; 27: 104-111

31 Söderquist J, Wijma B, Wijma K. The longitudinal course of post-traumatic stress after childbirth. J Psychosom Obst Gynaecol 2006; 27: 113-119

32 Ryding EL, Wijma B, Wijma K. Posttraumatic stress reactions after emergency cesarean section. Acta Obstet Gynecol Scand 1997; 76: 856-861

33 Chamberlain G. What is the correct caesarean rate? $\mathrm{Br} J$ Obstet Gynaecol 1993; 100: 403-404

34 Ryding EL, Wijma K, Wijma B. Experiences of emergency cesarean section: A phenomenological study of 53 women. Birth 1998; 25: 246251

35 Ringler M. Psychodynamische Aspekte traumatischen Geburtserlebens (Psychodynamic aspects of traumatic birth experience). Speculum 2001; 19: 23-27

36 Mezey G, Bacchus L, Bewly S et al. Domestic violence, lifetime trauma and psychological health of childbearing women. Br J Obstet Gynaecol 2005; 112: 197-204

37 Resnick HS, Kilpatrick DG, Dansky BS et al. Prevalence of civilian trauma and posttraumatic stress disorder in a representative national sample of women. J Consult Clin Psychol 1993; 61: 984-991

38 Brockington I. Motherhood and mental health. New York: Oxford University Press; 1996: 430-450

39 Marks MN. Characteristics and causes of infanticide in Britain. Int Rev Psychiatr 1996; 8: 99-106

40 Nesca M, Dalby JT. Maternal neonaticide following traumatic childbirth: a case study. Int J Offender Ther Comp Criminol 2011; 55: 1166-1178

41 McNally RJ, Bryant RA, Ehlers A. Does early psychological intervention promote recovery from posttraumatic stress? Psychol Sci 2003; 4: 4579

Deutschsprachige Zusatzinformationen mit deutschem Text online abrufbar unter: www.thieme-connect.de/ejournals/toc/gebfra. 